e-ISSN 2540-9840 p-ISSN 1412-3770

Accredited by Ministry of Research, Technology

and Higher Education No: 28/E/KPT/2019
Jurnal Ilmiah Sains, Oktober 2020, 20(2): 128-133

DOI: https://doi.org/10.35799/jis.20.2.2020.30073

Available online at https://ejournal.unsrat.ac.id/index.php/jis

\title{
Investigasi Anomali TEC Ionosfer Berkaitan Dengan Gempa Bumi Jailolo 15 Nopember 2019 Menggunakan Metode 2DPCA
}

\author{
Gloria R. Kaindeh ${ }^{1)}$, Seni H.Tongkukut ${ }^{1)}$, Gerald H. Tamuntuan ${ }^{1)}$, Ferdy Ferdy ${ }^{1)}$, \\ R. Telleng ${ }^{1}$, Mans Mananohas ${ }^{2}$, Dolfie P. Pandara ${ }^{1 *}$ \\ ${ }^{1)}$ Jurusan Fisika, Fakultas Matematika dan Ilmu Pengetahuan Alam, \\ Universitas Sam Ratulangi Manado \\ ${ }^{2)}$ Jurusan Matematika, Fakultas Matematika dan Ilmu Pengetahuan Alam \\ Universitas Sam Ratulangi Manado \\ ${ }^{*}$ dpandara_fisika@unsrat.ac.id
}

(Article History: Received 12-08-2020; Accepted 07-10-2020; Published 28-10-2020)

\begin{abstract}
ABSTRAK
Penelitian ini berfokus pada upaya menginvestigasi anomali Total Electron Content (TEC) ionosfer berkaitan dengan gempa bumi Jailolo yang terjadi pada tanggal 15 November 2019 pukul 01:17 Waktu Indonesia Timur (WIT) dengan menggunakan metode Two Dimensional Principal Component Analysis (2DPCA). Anomali TEC yang teridentifikasi oleh metode 2DPCA digunakan untuk menentukan prekusor dari gempa bumi Jailolo. Citra Global Ionosphere Maps (GIM) TEC selang tanggal 9-15 Nopember 2019 dianalisis dan dikonversi menjadi citra nilai Eigen menggunakan program Matlab_2DPCA. Berdasarkan citra nilai Eigen ditemukan bahwa pada tanggal 13 Nopember 2019 pukul 22:15 - 22:35 WIT telah terjadi anomali TEC ionosfer di atas episenter gempa bumi Jailolo dengan durasi 20 menit. Selama aktivitas pra seismik, ionosfer memberikan respon berupa penurunan nilai TEC. Anomali kandungan elektron total ionosfer merupakan suatu prekursor yang berasosiasi dengan pelepasan gas radon selama aktivitas pra seismik sebelum gempa bumi.
\end{abstract}

Kata Kunci: Anomali TEC; gempa bumi Jailolo; metode 2DPCA; nilai eigen; prekursor

\section{Investigation of Ionosphere TEC Anomalies Associated with the 15 November 2019 of Jailolo Earthquake Using the 2DPCA Method}

\begin{abstract}
This research focuses on investigating of the ionospheric total electron content (TEC) anomaly associated with the Jailolo Earthquake earthquake that occurred on November 15, 2019 at 01:17 Eastern Indonesian Time (WIT) using the 2DPCA method. The TEC anomaly identified by the 2DPCA method was used to determine the precursor of the Jailolo earthquake. Global ionosphere maps (GIM) TEC images between November 9-15, 2019 were analyzed and converted into several images of the Eigen value using the Matlab_2DPCA program. Based on Eigen value images, it was found that on November 13, 2019 at 22:15 - 22:35 WIT, an ionosphere TEC anomaly occurred above the epicenter of the Jailolo Earthquake with a duration of 20 minutes. During pre-seismic activity, ionosphere given a responds by decreasing of TEC value. The total electron content anomaly of the ionosphere is a precursor associated with the release of radon gas during pre-seismic activity before an earthquake.
\end{abstract}

Keywords: TEC anomaly; Jailolo earthquake; 2DPCA method; eigen value; precursor

\section{PENDAHULUAN}

Anomali TEC ionosfer dapat berasosiasi dengan aktivitas gempa bumi (Cahyadi \& Saputra, 2018). Anomali TEC tersebut berupa penurunan dan peningkatan $T E C$ di dekat zona persiapan gempa sebelum adanya gempa besar (Liu et al., 2006). Beberapa penelitian menunjukkan adanya kaitan antara gempa bumi dengan anomali 
TEC yang terjadi di ionosfir. Anomali TEC teramati beberapa jam sampai beberapa hari sebelum dan sesudah gempa (Fuying, 2011). Liu et al., 2004 menunjukkan terjadinya variasi TEC selang 1-5 hari sebelum gempa bumi Taiwan pada periode 1999-2002 dengan magnitudo gempa lebih dari $6 \mathrm{Mw}$. Singh et al. (2010) menunjukkan bahwa anomali TEC terlihat pula selang 1-2 hari sesudah gempa di India yang terjadi pada tanggal 8 Januari 2007 dengan 6,0 Mw dan tanggal 5 Mei 2007 dengan 6,2 Mw. Romanovskaya \& Namgaladze (2014) menemukan 32 kejadian gempa bumi yang didahului dengan kemunculan anomali TEC dari 43 kejadian gempa bumi yang menjadi obyek penelitiannya. Adil et al. (2019) menemukan adanya anomali pada TEC 3 hari sebelum gempa bumi pada Kaikoura 2016 di Selandia Baru dengan Magnitudo 7,8 Mw. Alcay (2016) mendeteksi adanya peningkatan TEC tiga hari sebelum hingga dua hari setelah gempa bumi Turki 7,2 Mw yang terjadi pada 23 Oktober 2011. Riset anomali TEC di Indonesia tahun 2014 menunjukkan adanya variasi anomali TEC yang muncul sebelum gempa bumi Jawa 25 Januari 2014 (6,2 Mw), gempa bumi Banda 6 Agustus 2014 (6,2 Mw), gempa bumi Maluku 10 September 2014 (6,2 Mw), gempa bumi Maluku Utara 15 November 2015 (7,2 Mw), Gempa bumi Banda 6 Desember 2014 (6,1 Mw) dan gempa bumi Maluku Utara 21 Desember 2014 (6,3 Mw) (Sunardi et al., 2015). Kaitan antara anomali TEC dan aktivitas gempa bumi sangat penting dalam upaya mitigasi bencana terutama dalam memprediksi terjadinya suatu gempa bumi.

Penelitian tentang anomali TEC akibat gempa telah dilakukan secara luas dengan berbagai metode (Freund, 2003; Pulinets, 2004; Sunardi et al., 2015; Cahyadi \& Saputra, 2018). Kajian anomali TEC dan kaitannya dengan aktivitas gempa bumi telah dikembangkan dan dipakai oleh Badan Meteorologi, Klimatologi dan Geofisika (BMKG) (Sunardi et al., 2015). Salah satu metode yang telah diimplementasikan dalam penelitian anomali TEC adalah metode 2DPCA. Metode 2DPCA digunakan dalam analisis data citra TEC. Lin, 2013 telah memanfaatkan metode 2DPCA untuk menginvestigasi anomali TEC ionosfer akibat gempa Tobelo yang terjadi pada tanggal 26 Agustus 2012 dengan magnitudo 6,6 Mw.
Hasil penelitian tersebut menunjukkan bahwa metode 2DPCA dapat memperlihatkan anomali $T E C$ sebelum terjadinya gempa bumi (Lin, 2013).

Metode 2DPCA sangat potensial digunakan dalam riset gempa bumi namun belum banyak diaplikasikan dalam riset prekursor gempa bumi di Indonesia. Metode ini merupakan metode penyederhanaan variabel dengan cara mereduksi data atau mencari karakteristik data dengan memetakan data dari dimensi semula ke dimensi yang relatif lebih rendah serta akan menghasilkan komponen utama (Shlens, 2014). Metode 2DPCA didasarkan pada sifat dan operasi matriks (Lin, 2013). Metode 2DPCA merupakan metode ekstraksi ciri dengan mencari nilai Eigen utama terbesar (Wijaya, 2017). Melalui metode ini, proses ekstraksi gambar akan lebih lebih efisien (Yang et al., 2004; Lin, 2013).

Pemanfaatan metode 2DPCA dalam analisis anomali TEC akibat gempa bumi sangat didukung oleh ketersediaan data citra GIM TEC dari berbagai lembaga geofisika dan antariksa dunia. Pemanfaatan data citra GIM $T E C$ dan analisisnya dengan metode $2 D P C A$ harus dioptimalkan mengingat sangat intensnya aktivitas gempa bumi di Indonesia. Analisis citra GIM TEC dengan metode 2DPCA diharapkan akan memberikan informasi-informasi yang berkaitan dengan adanya prekusor ionosferik dan sumber prekursor sebelum terjadinya suatu gempa bumi. Informasi-informasi tersebut merupakan informasi yang bersifat noveltis karena setiap gempa bumi dapat berkaitan dengan mekanisme sumber, kekuatan gempa, kandungan gas radon di litosfer, densitas udara di atmosfer dan mekanisme penjalaran gelombang akustik yang berbeda-beda. Penelitian ini bertujuan untuk mengidentifikasi prekusor gempa bumi yang terjadi di Barat Laut Jailolo Maluku Utara (gempa bumi Jailolo) pada tanggal 15 November 2019 menggunakan metode 2DPCA.

\section{METODE PENELITIAN}

Penelitian ini dilakukan di Laboratorium Geofisika Jurusan Fisika FMIPA Unsrat Manado selang Januari-Juni 2020. Data utama dari penelitian ini adalah data citra GIM TEC yang di unduh dari Global 
Differential GPS System (GDGPS) setiap 10 menit selama 6 hari sebelum gempa yaitu data tanggal 9-15 November 2019 website (http://www.gdgps.net/products/tec-

maps.html). Data pendukung untuk riset ini adalah data gempa bumi yang diunduh dari katalog USGS (https://earthquake.usgs.gov/ earthquakes/search/) untuk kategori gempa berkekuatan lebih dari $6 \mathrm{Mw}$ selama tahun 2019. Berdasarkan data gempa tersebut dipilih gempa bumi yang terjadi pada tanggal 15 November 2019 Pukul 01:17 WIT (UTC+9) di Barat Laut Jailolo Maluku Utara pada koordinat $1,62^{\circ} \mathrm{LU}$ dan $126,42^{\circ} \mathrm{BT}$ dengan magnitude $7,1 \mathrm{Mw}$ serta kedalaman $33 \mathrm{~km}$. Data pendukung lain yang digunakan adalah data indeks Disturbance Storm Time (DST) yang diunduh dari website http://wdc.kugi. kyoto-u.ac.jp. Data indeks DST akan digunakan untuk mengklarifikasi status badai magnetik bumi pada hari kejadian gempa.

Data citra GIM TEC selama 6 hari diolah menggunakan metode ekstraksi ciri utama pada citra dengan teknik 2DPCA. Metode tersebut telah diimplementasikan menjadi program Matlab_2DPCA. Melalui program tersebut akan dikomputasi nilai Eigen utama dan dikonstruksi citra nilai Eigen pada setiap grid citra yang ditampilkan dalam variasi warna grid dengan rentang nilai $0-1$. Apabila nilai Eigen besarnya 0 hingga 0,4 maka akan terlihat warna ungu pada grid dan berarti tidak terjadi anomali TEC. Sedangkan bila nilai Eigen besarnya 0,5 sampai 1 maka akan terlihat warna coklat sampai kuning pada grid yang menyatakan adanya anomali TEC Ionosfer (Lin, 2013). Nilai Eigen utama pada lokasi gempa bumi Jailolo $\left(1,62^{\circ} \mathrm{LU}\right.$; $\left.126,42^{\circ} \mathrm{BT}\right)$ dari setiap citra selama 6 hari diinvestigasi untuk menemukan adanya anomali nilai TEC. Selanjutnya untuk menentukan sumber anomali dipakai nilai indeks $D S T$ sebagai pembanding.

\section{HASIL DAN PEMBAHASAN}

Data citra GIM TEC selang 9-15 Nopember 2019 menunjukkan variasi nilai TEC secara global setiap 10 menit dan tidak dapat menunjukkan adanya anomali. Sampel data citra GIM TEC tanggal 13 Nopember 2019 pukul 22:15 - 22:35 WIT menunjukkan variasi nilai TEC di atas Jailolo cukup rendah $\left(1,62^{\circ} \mathrm{LU}\right.$ dan $\left.126,42^{\circ} \mathrm{BT}\right)$ dan bervariasi antara 4-6 TECU (Total Electron Content
Unit) seperti diperlihatkan pada Gambar 1. Sampel citra tersebut telah diolah dengan Program Matlab_2DPCA untuk menginvestigasi adanya anomali TEC.

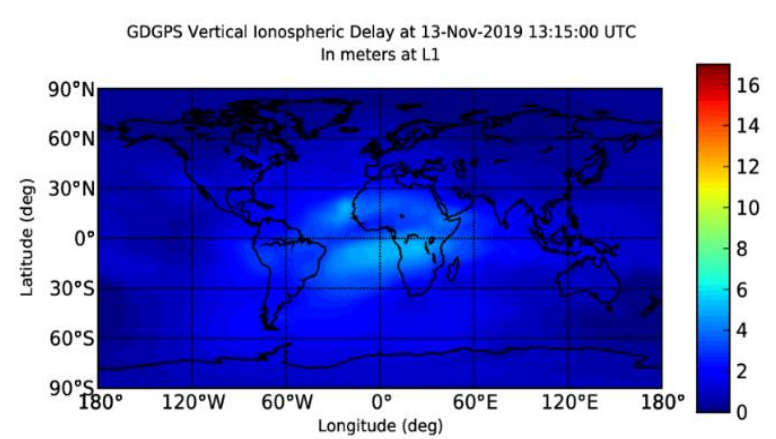

(a)

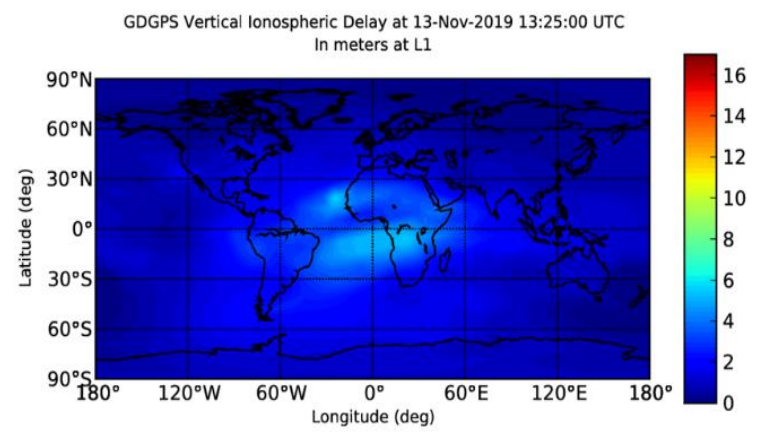

(b)

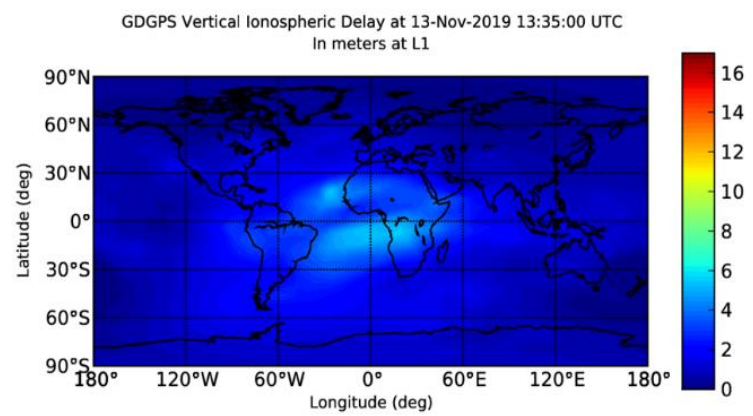

(c)

Gambar 1. Citra GIM-TEC (a) 13 November 2019 pukul 22:15 WIT (UTC+9), (b) 13 November 2019 pukul 22:25 WIT dan (c) 13 November 2019 pukul 22:35 WIT

Implementasi metode 2DPCA terhadap ketiga citra pada Gambar 1 di atas menghasilkan citra nilai Eigen utama seperti pada Gambar 2. Gambar 2 menunjukkan adanya variasi warna citra pada daerah sekitar episenter Gempa Jailolo pada tanggal 13 Nopember 2019 pukul 22:15-22:35 WIT. Intensitas warna pada Gambar 2 digunakan untuk menunjukkan besarnya nilai eigen pada 600 grid pada citra. Bujur sangkar berwarna hijau yang ada dalam kotak-kotak Eigenvalue of 2DPCA menunjukkan lokasi titik Gempa 
Jailolo. Hasil pengujian dari data citra GIMTEC menunjukkan nilai Eigen lebih dari 0,5 disekitar titik gempa terjadi satu hari sebelum gempa yaitu pada tanggal 13 Nopember 2019 Pukul 22:15-22;35 WIT. Nilai Eigen pada pukul 22:15 WIT sebesar 0,510 (Gambar 2a), nilai Eigen pada pukul 22:25 WIT sebesar 0,506 (Gambar 2b) dan nilai Eigen pada pukul 22:35 WIT sebesar 0,688 (Gambar 2c). Nilai Eigen yang melebihi angka 0.5 pada periode waktu 22:15 WIT hingga 22:35 WIT menunjukkan terjadinya anomali TEC ionosfer di atas episenter gempa (Lin, 2013). Resolusi citra warna nilai Eigen antara Gambar 2a dan Gambar 2b sangat kecil karena perbedaan nilai Eigennya juga sangat kecil yaitu 0,004. Resolusi citra Gambar 2b lebih mendekati warna violet atau mendekati resolusi citra yang bernilai Eigen 0,500. Variasi nilai Eigen pada selang waktu 22:1522:35 WIT di atas menunjukkan variasi intensitas anomali. Variasi intensitas anomali TEC secara teoritis berkaitan dengan fluktuasi sumber prekusor.

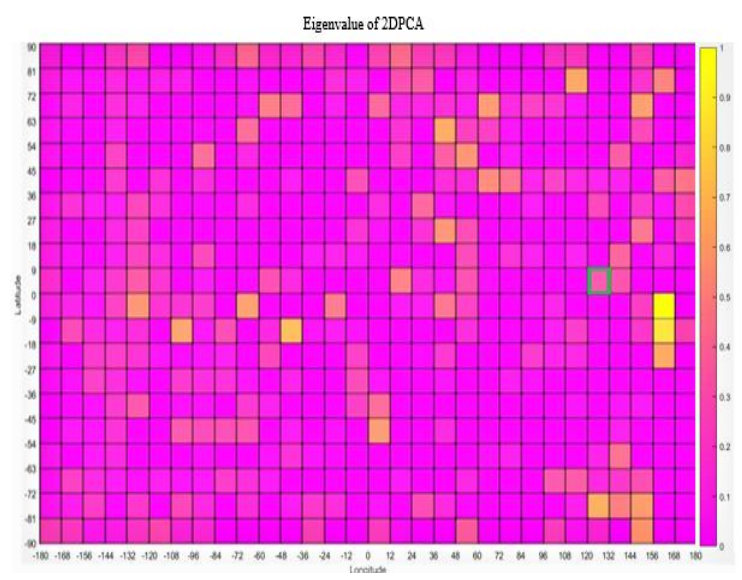

(a)

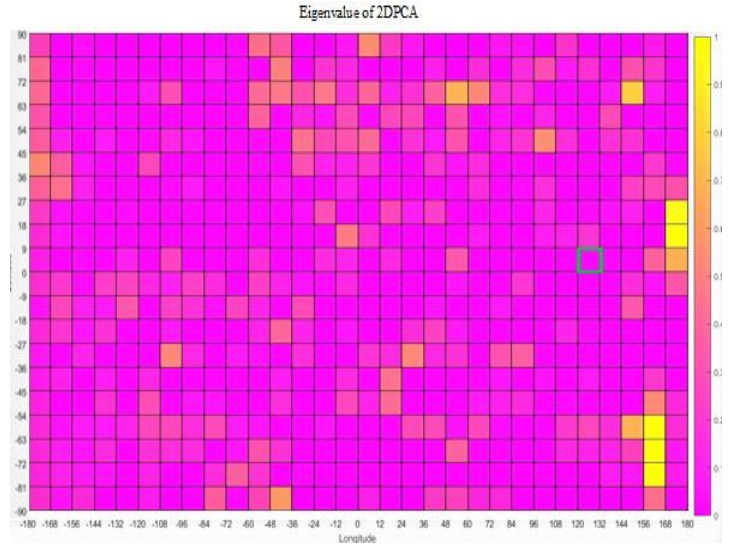

(b)

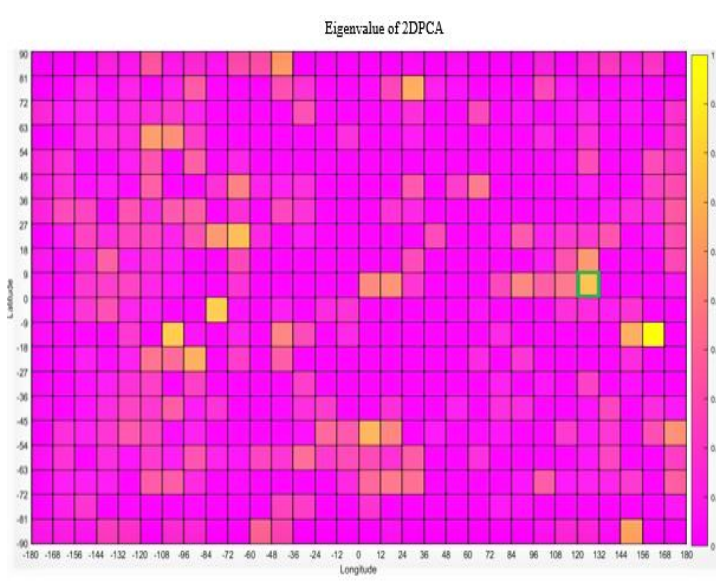

(c)

Gambar 2. Citra Nilai Eigen Utama (a) 13 November 2019 pukul 22:15 WIT, (b) 13 November 2019 pukul 22:25 WIT dan (c) 13 November 2019 pukul 22:35 WIT

Deteksi anomali TEC dengan metode 2DPCA berhasil menunjukkan perubahan signifikan kondisi ionosfer sekitar 20 menit dari pukul 22.15 WIT sampai pukul 22:35 WIT pada 13 Nopember 2019 atau terjadi satu hari sebelum gempa. Durasi anomali TEC yang singkat tersebut bersesuaian pula dengan hasil dari beberapa peneliti. Lin (2013) menunjukkan adanya respon ionosfer terhadap aktivitas gempa Tobelo 26 Agustus 2012 yang berlangsung sekitar 10 menit dari pukul 15:10 WIT hingga 15:20 WIT. Durasi waktu anomali TEC yang singkat juga ditunjukkan pada saat terjadi gempa bumi di Iwate-Miyagi Nairiku, Jepang $(7,2 \mathrm{Mw})$ pada 13 Juni 2008 (Lin, 2011). Hasil penelitian ini dan penelitian-penelitian sebelumnya menunjukkan bahwa metode 2DPCA secara akurat dapat menggambarkan anomali $T E C$ ionosfer sebelum terjadinya gempa bumi. Hasil penelitian ini juga menunjukkan bahwa anomali TEC sebelum gempa bumi Jailolo tidak berkaitan dengan badai magnetik sebab nilai indeks DST selang tanggal 1-20 Nopember $2019 \geq-23,4$ nT seperti tampak pada Gambar 3. Badai magnetik akan mulai berpengaruh apabila badai sudah berstatus aktif dengan nilai indeks DST di antara $-44,9$ nT sampai -25,5 nT (Santoso et al, 2016). Badai magnetik tidak boleh diabaikan pengaruhnya. Badai magnetik merupakan faktor eksternal yang sangat kuat dan dapat menurunkan nilai indeks DST (Belekubun et al, 2019). 


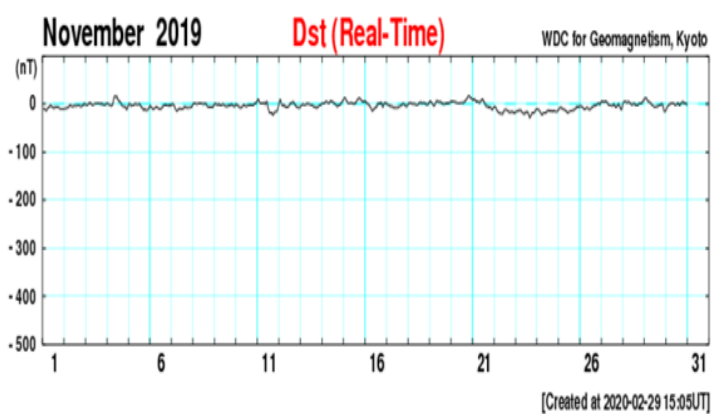

Gambar 3. Indeks DST Bulan Nopember 2019

Adanya anomali TEC dapat dipandang sebagai penanda awal (prekursor) untuk persiapan gempa bumi (Liu et al., 2011). Anomali TEC ionosfer tidak berkaitan langsung dengan gempa bumi karena fakta bahwa gempa bumi berpusat dan terjadi di bawah kerak bumi. Beberapa mekanisme yang mungkin menyebabkan anomali TEC telah diungkapkan oleh beberapa peneliti. Menurut Jin et al. (2010), anomali TEC mungkin disebabkan oleh gelombang akustik. Gelombang akustik menciptakan gangguan pada ionosfer karena adanya getaran di permukaan tanah dan efek alami dari penurunan kepadatan dengan ketinggian atmosfer (Lin, 2013). Faktor lain yang mungkin adalah adanya medan listrik yang menciptakan penyimpangan skala besar dalam densitas ionosfer baik dari pelepasan gas radon atau dari variasi tegangan di antara batuan di sekitar episentrum gempa bumi (Pulinets, 2004; Freund, 2003). Banyak penelitian menunjukkan hubungan antara gempa dangkal dan anomali TEC namun gempa bumi yang besar dan dalam dapat juga berpengaruh (Pulinets, 2004). Pada saat terjadi gempa besar, gas radon dapat dilepaskan melalui retakan mikro di permukaan bumi. Gas radon dapat mengurangi medan listrik di atmosfer dan dapat melakukan perjalanan tanpa hambatan ke ionosfer di sepanjang garis geomagnetik (Pulinets, 2004). Radon yang terkonsentrasi di air dan tanah bisa dilepaskan dengan cepat karena tekanan tinggi di zona persiapan gempa bumi yang dalam. Pelepasan cepat gas radon dapat direspon oleh ionosfer dalam durasi watu yang singkat sekitar 10-30 menit. Dengan demikian aktivitas pra seismik sebelum gempa bumi dapat direspon oleh ionosfer dan dapat menjadi penanda terjadinya suatu gempa bumi.

\section{KESIMPULAN}

Penelitian ini menunjukkan bahwa aktivitas pra seismik gempa bumi Jailolo 15 Nopember 2019 pukul 01:17 WIT dapat dideteksi pengaruhnya di ionosfer dengan metode 2DPCA. Aktivitas pra seismik yang terjadi tanggal 13 Nopember 2019 pukul 22.15-22.35 WIT telah mengakibatkan anomali TEC pada lapisan ionosfer yang bersesuaian dengan titik episenter gempa. Aktivitas pra seismik berkaitan dengan pelepasan gas radon telah menimbulkan gangguan pada konsentrasi elektron dalam durasi waktu yang singkat sekitar 20 menit. Keberadaan gas radon dan kaitannya dengan variasi nilai Eigen citra TEC tersebut perlu diinvetsigasi lebih lanjut dengan metode penelitian yang lain. Kajian dengan metode 2DPCA ini perlu dikembangkan pula dengan mengintegrasikannya dengan sistim syaraf tiruan atau logika fuzzy.

\section{UCAPAN TERIMA KASIH}

Penelitian ini didanai dari Hibah Penelitian RDUU Unsrat 2019. Tim peneliti menyampaikan terima kasih kepada Rektor Universitas Sam Ratulangi Manado yang telah memberikan bantuan dana hibah tersebut.

\section{DAFTAR PUSTAKA}

Adil, M.A., R.A. Abdul \& S. Munawar. Earth Ionosphere Anomalies before the 2016 Kaikoura Earthquake New Zealand from OLR and GPS-TEC; 2019. Proceeding Institut of Space Technologi.

Alcay, S. 2016. Analysis of Ionospheric Tec Variations Response To The Mw 7.2 Van Earthquake. Acta Geodyn. Geomater, 13(3): 257-262.

Belekubun, A.F., S.H.J. Tongkukut, Asnawi \& D.P. Pandara. 2019. Respon Ionosfer Terhadap Badai Matahari Berdasarkan Analisis Kandungan Elektron Total dan Indeks Gangguan Geomagnet. Jurnal MIPA Unsrat online, 8(2): 82-85. 
Cahyadi, M.N. \& F.A. Saputra. 2018. Perbandingan Perubahan Total Electron Content (TEC) Ionosfer Akibat Gempa Bumi dan Gunung Api (Studi Kasus: Gempa Bumi 2 Maret 2016 dan Gunung Merapi 2010). Geoid., 12(2): 195-201.

Freund, F.T. 2003. Rocks that crackle and sparkle and glow strange preearthquake phenomena. $J$ sci explor., 17(1): 37-71.

Fuying, Z., W. Yun, Z. Yiyan \& L. Jian. 2011. A Statistical Investigation of PreEarthquake Ionosphere TEC Anomalies. Geodesy and Geodynamics, 2(1): 61-65.

Jin, S., W. Zhu \& E. Afraimovich. 2010. Coseismic ionospheric and deformation signals on the 2008 magnitude 8.0 Wenchuan earthquake from GPS observations. Int. $J$ Remote Sens, 31(13): 3535-3543.

Lin, J.W. 2013. Ionospheric Anomaly Due to the Volcanic Eruption in Colima, Mexico, 06 January 2013: TwoDimensional Principal Component Analysis. European Jornal of Remote Sensing, 46: 689-698.

Liu, C. 2004. Gabor-based kernel PCA with fractional power polynomial models for face recognition. IEEE Trans. Pattern Anal. Mach. Intell., 26(5): 572-581.

Liu, J.Y., B.T. Yi, F.M. Kuo, I.C. Yuh, F.T. Ho, H.L. Chien, K. Masashi \& P.L. Chien. 2006. Ionospheric Gps Total Electron Content $(\mathrm{Tec})$ Disturbances Triggered By The 26 December 2004 Indian Ocean Tsunami. Advance Earth and Space Science, 71.

Liu, J.Y., C.H. Chen, C.H. Lin, H.F. Tsai, C.H. Chen \& M. Kamogawa. 2011. Ionospheric disturbances triggered by the 11 March 2011 M9.0 Tohoku earthquake. $J$ Geophys Res., 116: A06319.

Lin, J.W. 2011. Seismo-ionospheric disturbance using principal component analysis a study of Japan's IwateMiyagi Nairiku earthquake on 13 June 2008. Acta Geod Geophys Hung, 46(1): $1-9$.
Lin, J.W. 2013. Ionospheric Anomaly Due to the Volcanic Eruption in Colima, Mexico, 06 January 2013: TwoDimensional Principal Component Analysis. European Jornal of Remote Sensing, 46: 689-698.

Pulinets, S. \& K. Boyarchuk. 2004. Ionospheric Precursors of Earthquakes. Springer, Berlin.

Romanovskaya, Y.V. \& A.A. Namgaladze. 2014. Seismo-Ionospheric Precursors Of Strong Earthquakes: Analysis Of Total Electron Content Observations. Proceedings of the 10th Intl Conf. "Problems of Geocosmos, St. Petersburg, Russia.

Santoso, A., N. Dadang, J. Mira, E.R. Iyus, E. Sri, W. Anton \& F. Siska. 2016. Analisis Pengaruh Badai Geomagnet Terhadap Resnpon FoF2 Ionosfer di BPAA Sumedang. Prosiding Seminar Nasional Sains Antariksa.

Shlens, J. 2014. A Tutorial on Principal Component Analysis. Google Research Mountain View CA 94043. https://www.cc.gatech.edu/ Isong/teac hing/CX4240spring16/pca_schlens.pdf.

Singh, S., K. Arvind, S.B. Bikramjit, M. Sandeen \& K.S. Vinod. 2010. Radon monitoring in soil gas and ground water for earthquake prediction studies in North West Himalayas, India. Terrestrial, Atmospheric and Oceanic Sciences, 21(4): 6.

Sunardi, B., B. Muslim \& S. Pakpahan. 2015. Anomali Total Electron Content (TEC) Sebelum Gempabumi Kuat di Indonesia Tahun 2014. Prosiding Seminar Nasional Fisika.

Wijaya, W.Y. 2017. Identifikasi Bahan Jenis Kulit Menggunakan Metode 2DPCA dan LVQ Pada Citra Digital. [Skripsi]. Universitas Komputer Indonesia.

Yang, J., D. Zhang, A.F. Frangi \& J.Y. Yang. 2004. Two Dimensional PCA: A New Approach to Appearance-Based Face Representation and Recognition. IEEE Transaction on Pattern Analysis and Machine Intelligence, 26(1): 131-137. 